\title{
La producción de conocimiento en la investigación acción pedagógica (IAPE): balance de una experimentación
}

\author{
Rafael Avila Penagos \\ Universidad Pedagógica Nacional
}

\section{Resumen}

Este artículo recoge las lecciones derivadas de una segunda experimentación con una metodología de trabajo co-operativo, diseñada para operacionalizar una modalidad de la investigación acción pedagógica (IAPE). El autor sostiene que el principio rector de cualquier modalidad de la IAPE es el principio de reflexividad, y que el horizonte de cualquiera de esas modalidades es el de generar condiciones de posibilidad para la reflexión. Destaca, en seguida, cuatro de esas condiciones: i) ejercicio intensivo en la objetivación del discurso por medio de prácticas escriturales, ii) ejercicio intensivo en objetivación de la práctica pedagógica por medio de prácticas de auto-observación, con la ayuda del audiovideo, iii) ejercicio intensivo del trabajo en equipo con responsabilidades individuales definidas, y iv) ejercicio intensivo de argumentación e interlocución crítica entre pares, siempre mediadas por textos escritos.

La capacidad de esta herramienta para objetivar al sujeto de la práctica pedagógica, en un ámbito de interlocución crítica y responsabilidad compartida, crea las condiciones para que la subjetividad individual de los maestros se sienta incluída en una subjetividad colectiva que es, finalmente, la responsable de la construcción de sentido. Al pasar de una práctica pedagógica individual a una práctica pedagógica colectiva, y de un estilo individual de reflexión a un estilo colectivo de reflexión sobre la práctica, la determinación del sentido pasa a ser una responsabilidad del colectivo. Es decir: un asunto de interés público.

\section{Palabras claves}

Investigación acción pedagógica - Práctica pedagógica cooperativa - Reflexión pedagógica - Reflexividad pedagógica. 


\title{
The production of knowledge in the pedagogical action research (PAR): appraisal of an experiment
}

Rafael Avila Penagos

National Pedagogical University

\begin{abstract}
This article brings together the lessons learned from a second experiment with a methodology of cooperative work designed to implement a modality of pedagogical action research (PAR). The author maintains that the governing principle of any modality of PAR is the principle of reflectivity, and that the horizon of any of these modalities is to generate conditions of possibility for the reflection. The text highlights four of these conditions: i) the intensive exercise of the objectivation of the discourse through writing practices; ii) the intensive exercise of the objectivation of pedagogical practice through practices of self-observation with the aid of audio and video; iii) the intensive exercise of group work with well-defined individual responsibilities; iv) the intensive exercise of argumentation and critical dialogue between peers, always mediated by written texts.

The ability of this tool to objectify the subject of the pedagogical practice within a context of critical dialogue and shared responsibility creates the conditions for the teachers' individual subjectivities to feel included in a collective subjectivity, which is ultimately responsible for the construction of meaning. By moving from an individual pedagogical practice to a collective pedagogical practice, and from an individual style of reflection to a collective style of reflection about the practice, the definition of meaning becomes a responsibility of the collective. In other words: a subject of public interest.
\end{abstract}

\section{Keywords}

Pedagogical action research - Cooperative pedagogical practice Pedagogical reflection - Pedagogical reflectivity. 


\section{El proyecto y su horizonte}

La experimentación a la cual hace alusión este trabajo corresponde al Proyecto DSI-02003, "Las prácticas pedagógicas en la formación de lectores y escritores"1, diseñado y ejecutado por miembros del grupo de investigadores denominado "Sujetos y nuevas narrativas en la investigación y enseñanza de las ciencias sociales", desde el Centro de Investigaciones de la Universidad Pedagógica Nacional (CIUP) en Bogotá, Colombia ${ }^{2}$.

La preocupación permanente del grupo en torno a los problemas metodológicos propios de la producción de conocimiento social, lo ha llevado a ensayar algunas modalidades de la Investigación Acción Pedagógica (IAPE en adelante) ${ }^{3}$ con el fin de construir y/o reconstruir herramientas que le permitan auscultar los laberintos de la cultura escolar, sobretodo en lo que se refiere a las prácticas pedagógicas de sus actores protagónicos: los maestros. En el caso que nos ocupa, el horizonte del proyecto arriba mencionado es el de poner a prueba un "artefacto cultural" diseñado para generar condiciones de reflexión sobre las prácticas pedagógicas, a partir de un conjunto de ejercicios, procedimentalmente organizados como una secuencia metodológica.

\section{La reflexión: el núcleo duro de la IAPE}

Si entendemos por investigación social un proceso ordenado de indagación, a partir de preguntas, que busca describir, comprender o explicar los motivos y finalidades, los significados y los sentidos, los supuestos y los postulados de los procesos y las prácticas de interacción entre sujetos individuales o colectivos, la IAPE es, sin lugar a dudas, una modalidad de investigación social que busca explorar las intimidades de las prácticas pedagógicas, en el ámbito de la escuela.

Está diseñada para realizar un tipo de investigación en la cual el sujeto y el objeto de la investigación se superponen. El sujeto que diseña las prácticas y las despliega al ponerlas en escena, es el mismo que vuelve sobre ellas (sus prácticas) para tomarlas como objeto de estudio, explicitando los problemas y las preguntas que "surgen" de los agujeros y de los intersticios de su práctica. Partimos, entonces, del supuesto de que la práctica pedagógica no es translúcida; al contrario, está llena de agujeros y de oscuridades que pueden reconstruirse en forma de preguntas desde una determinada "ventana de observación" .

Su principio rector es el de la reflexividad, un recurso propio del sujeto para volver sobre sus "pasos", el cual necesita un ambiente y unas condiciones que lo hagan posible y, ojalá, habitu$\mathrm{al}^{5}$. El sociólogo y pedagogo Emile Durkheim (1985) le dió tanta importancia que la situó, como columna vertebral, en su conceptualización de la pedagogía. Stenhouse (1987) la concibe como una maravillosa sintesis entre la tradición experimentalista de las ciencias naturales y la observación naturalista de las ciencias sociales; y en la obra de D. Schon (1992) como es bien sabido, la reflexión se convierte en el rasgo fundamental de un profesional inteligente. P. Bourdieu (1990), en su famosa lección sobre la lección, consideró como una propiedad fundamental de la práctica sociológica, la voluntad de objetivar el sujeto de la práctica científica. Y elevó está propiedad a la condición de principio de reflexividad.

1. Equipo responsable del Proyecto: Mauricio Pérez Abril y Daniel Torres Ardila (coinvestigadores) Milena Barrios Martínez y María Claudia Soler (asistentes de investigación) Gloria Lara Vargas (auxiliar de videograbación) y Rafael Avila Penagos (investigador principal).

2. El grupo ha sido reconocido por COLCIENCIAS, en la Convocatoria a Grupos colombianos de Investigación científica o tecnológica 2002 y 2004, y ha sido considerado como uno de los soportes investigativos tanto de la Maestría en Educación de la UPN, como del Doctorado Interinstitucional en Educación, en el cual participan La Universidad del Valle, la Universidad Distrital y la Universidad Pedagógica Nacional de Bogotá (Colombia S.A.).

3. Utilizamos la sigla IAPE (investigación acción pedagógica) para distinguirla de la IAP (investigación acción participativa).

4. Son las ventanas y los cuadros pictóricos los que nos han llevado a tomar consciencia de que nuestra observación ocurre desde un punto de vista (concepto de perspectiva) y, por añadidura, en-marcada 0 en-cuadrada en una obra ya comenzada. Sobra decir que estoy aludiendo al papel de la teoría, un tema que merece tratamiento específico y diferencial.

5. El Profesor José Carlos Libâneo (2002) distingue, al menos, tres significados de reflexividad. 
Desde este punto de vista, la modalidad de la IAPE que hemos puesto a prueba en los dos últimos proyectos ${ }^{6}$, puede conceptualizarse como un diseño experimental de un "artefacto cultural" destinado a crear las condiciones favorables para habitualizar la reflexión sobre sus propias prácticas o, para decirlo a la manera de Bourdieu, un artefacto cultural destinado a generar el hábito de la auto-objetivación del sujeto de la práctica pedagógica ${ }^{7}$, en un ambiente interactivo de co-operación.

\section{Escuchar la palabra del maestro}

La IAPE toma en serio la palabra del maestro, esa primera palabra que nos precede cuando llegamos a la escuela. No llega propiamente a observar, desde afuera, la experiencia de los maestros, llega a crear las condiciones y los escenarios para que los maestros puedan hablar sobre sus propias experiencias, direcciona su oreja para escuchar sus voces, se siente interpelada por la polifonía de sus discursos. Se provee de prótesis para prolongar sus oídos y registrar la pluralidad de esos discursos (la grabadora es videograbadora pero también audiograbadora). Es más una coordinación del habla con la escucha que pone en correspondencia los oídos de los investigadores con las bocas de los maestros. La palabra que sale de su boca y la que entra en el oído expectante del investigador es el hilo de Ariadna, y la aguja de Penélope que teje la trama entre estos dos tipos de sujetos.

A diferencia del maestro que llega a narrar, discurrir, relatar, contar, disertar, explicar, el investigador llega a escuchar. Saber escuchar, permanecer escuchando, sin distraer la atención, sin evadirnos del escenario con la imaginación, como quien está sintonizado con el otro, tratando de seguirlo, en actitud de respeto y de curiosidad al mismo tiempo, no es fácil. El oír como el ver es natural, pero el escuchar como el mirar son resultado de la educación. El sujeto nace con la capacidad de oír, pero tiene que aprender a escuchar, debe entrenarse y ejercitarse para construir el saber escuchar y convertirlo en habilidad, en destreza, en competencia habitualizada.

Este papel protagónico del escuchar, como instrumento de investigación, implica un desplazamiento fisiológico del ojo hacia la oreja, y un desplazamiento epistemológico del mirar hacia el escuchar. Digo "epistemológico" en cuanto cambia el vehículo y la fuente de la información. Pero no quiero significar que el sensor ojo sea sustituído por el sensor oído sino, más bien, que este último se vuelve más importante que el ojo, en la investigación social. Con el ojo llegamos a la superficie del sujeto (su cuerpo) que, en el mejor de los casos, funciona como "indicador" de los estados de ánimo; con el oído, en cambio, llegamos a la profundidad del sujeto (a su subjetividad) por medio del lenguaje. $Y$ esta parece ser una cualidad distintiva, no solo de la investigación de la cultura escolar, sino también de la inves-tigación social, en general.

\section{Objetivar el lenguaje}

Que la IAPE tome en serio la palabra del maestro significa también, y en primera ins-tancia, que el maestro debe tomar en serio su propia palabra como objeto de reflexión. No es posible objetivar el sujeto de la práctica, sin objetivar el lenguaje del sujeto. La reflexión comienza por casa; primero la reflexión sobre mi palabra, luego la reflexión sobre la palabra de los otros. La manera como el maestro nombra sus prácticas, sus ámbitos, sus procedimientos e instrumentos, e incluso la manera de nombrarse a sí mismo, no es indiferente a la estructura de su práctica. Por el contrario: está instalada en el corazón de la misma, mediando las relaciones del sujeto con el mundo y, por consiguiente, la relación del maestro con sus prácticas.

6. La primera experimentación ocurrió en el año 2002. Ver Libâneo "Aluna, lecciones de una experiencia de formación de maestros para la investigación" en La investigación acción pedagógica, experiencias y leccciones, Ediciones Antropos, Bogotá, 2003.

7. El objetivo de un trabajo complementario podría ser el de estudiar las relaciones de este "artefacto cultural" con la cibernética social, la observación de segundo orden y la hermenéutica de segundo orden. 
El lenguaje, entonces, es parte del problema que es preciso resolver en el examen de la práctica. Para modificar las prácticas del maestro, o las de cualquier otro sujeto, es preciso someter su universo lingüístico a un examen minucioso. Las maneras de nombrar no son inocentes, están cargadas de precomprensiones que no pueden acceder a la conciencia sino mediante procesos de objetivación lingüística. De modo que, para formar un profesional reflexivo, es preciso habituarlo a usar el lenguaje para reflexionar sobre el lenguaje, a usar el habla para reflexionar sobre el habla, a usar de su conversación para conversar sobre sus conversaciones, en suma: habituarlo a "lenguajear sobre el lenguaje" (Zea, 2004, p. 11).

\section{La divergencia de motivaciones en la investigación social}

Cuando el investigador social llega al escenario de su indagación, en el trabajo de campo, se encuentra con una tensión, más o menos patente, más o menos latente, que resulta de la divergencia de motivaciones entre el investigador y los investigados. Para resolver esta tensión, los investigadores se han inventado varios caminos: el de los informantes, indirecto y con sus consabidos riesgos; el de la manipulación, deshonesto porque oculta lo que quiere: "arrancarle" la información al otro; y el de la negociación, cuando se ponen sobre la mesa las diferentes motivaciones y se logran acuerdos de complementariedad. Sin la colaboración activa de los investigados es muy difícil obtener resultados satisfactorios en un proyecto de investigación social. Hay que buscarla por medio de procesos de negociación, o de persuasión, previos al despegue de un proyecto de investigación de esta índole (Zamosc, 1985).

Para comprender la manera como la IAPE resuelve este problema, es preciso distinguir entre dos modalidades de investigación: una la investigación sobre educación y otra la inves-tigación en educación (Stenhouse 1987, p. 42). La primera es la que se hace desde afuera (from outside) desde perspectivas disciplinarias distintas a la de la pedagogía, como la sicología, la sociología, la antropología, la lingüística, etc. por investigadores que no están directamente involucrados en la práctica educativa. La segunda es la que se hace desde adentro (from inside) por sujetos directamente involucrados en la práctica de la educación, que deciden tomar como objeto de estudio su propia práctica, movidos por la voluntad de transformar la realidad escolar.

Nuestro colega, el Profesor Mauricio Pérez Abril, llama a la primera modalidad "Modelo Olimpo", y a la segunda modalidad "Modelo Ágora" (Pérez Abril, 2003). Y el Profesor José Carlos Libâneo (2004), refiriéndose a la política de formación de profesores, utiliza dos enfoques:

A análise externa trata da formação de professores a partir de um olhar mais global... pode-se dizer que analisa os fatores da formação, de fora para adentro. A análise interna aborda os objetivos e conteúdos da formação... isto é, os processos internos da formação, embora sem perder de vista os contextos.

A los primeros los llama factores externos y a los segundos factores internos.

\section{Los estilos de articulación en el modelo Olimpo}

No es mi propósito limitarme a ubicar la IAPE en el conjunto denominado "modelo ágora”, lo que más me interesa es describir los estilos de articulación de los investigadores con la realidad escolar, en los dos modelos. El modelo Olimpo ha recurrido a dos estilos de articulación con la realidad escolar:

el estilo cuantitativo se ha articulado a través de encuestadores que incursionan en la escuela, dotados de instrumentos previamente diseñados para la "recolección" de información. Se supone, obviamente que, al 
terminar su incursión, salen de allí con todos los "datos" necesarios para la tabulación ${ }^{8}$. El investigador diseña los instrumentos y "tabula" los datos, siempre desde afuera.

el estilo cualitativo se articula a través del grupo de referencia, un grupo de maestros, previamente seleccionado, cuya colaboración consiste en traer, o llevar la información (primera lectura) a un escenario en donde los investigadores están presentes para hacer un primer análisis, con la participación de los maestros, y en donde los investigadores han instalado un dispositivo de registro (grabadoras o videograbadoras) que va a servir de soporte para la interpretación (segunda lectura). El investigador diseña todo el proceso y puede hacer que los maestros se involucren más o menos pero, finalmente, siempre conserva una distancia metodológica que lo mantiene "afuera", como el último responsable de sus conclusiones ante el mundo académico.

\section{Los estilos de articulación en el modelo Agora}

¿Cuáles son, entonces, los estilos de articulación del modelo Agora con la realidad escolar? Lo fundamental en este modelo, para que la investigación ocurra desde adentro, es que los maestros sean los sujetos de la investigación. Pero es posible imaginar dos situaciones: una en la que los maestros investigadores toman como objeto de investigación las prácticas de sus colegas u otros aspectos de la cultura escolar, y otra en que los maestros investigadores toman como objeto de estudio sus propias prácticas. Solo en este último caso podemos hablar de IAPE. El estilo de articulación varía, obviamente, según los estilos.

La situación ideal de autonomía sería que la iniciativa de la investigación surgiera de los maestros, y que fueran ellos mismos quienes diseñaran y llevaran a cabo el proyecto. La realidad es otra: en nuestro caso, la iniciativa y el diseño han sido nuestros; para la ejecución del Proyecto hemos negociado con las Directivas de un Colegio concreto y hemos recurrido a la persuasión para ganar la colaboración de los maestros. El interés de mejorar sus prácticas, de su parte, y el interés nuestro de probar el artefacto, provocan una situación de convergencia de motivaciones e intereses que facilita la negociación.

Nuestra idea era la de poner a prueba lo que venimos llamando un "artefacto cultural", inspirado en la IAPE, para que los maestros se iniciaran en la experiencia de investigar sus propias prácticas. No era nuestro deseo hacer la investigación por nuestra cuenta sino, más bien, inducir a los maestros a utilizar nuestro artefacto para hacer la investigación. Para ello pusimos a su disposición toda la "caja de herramientas" y explicamos el sentido de cada uno de los pasos; enseguida nos pusimos a distancia, como los apuntadores del teatro, con el fin de intervenir cuando, y solamente cuando, alguno de los actores "olvidara” el libreto.

Como autores de la "criatura" queriamos verla funcionar por su cuenta, y limitarnos al papel de asesores, tutores, o impulsores. La verdad es que, queriéndolo o no, teníamos que intervenir frecuentemente para orientar la actividad. Los maestros se autocualificaron en el proceso, de una manera sorprendente para ellos mismos, y se embelesaron con la auto-observación, por medio del audiovideo, hasta el punto de que comenzaron a habitualizar la reflexión; pero la mirada global y la lectura final de la experiencia fue responsabilidad de nuestro equipo.

\section{Cuatro insuficiencias, cuatro estrategias}

El diseño de eso que hemos llamado provisionalmente un "artefacto cultural", no es una invención arbitraria, sino que está deliberadamente elaborado para subsanar

8. Tabular significa expresar valores, magnitudes u otros datos, por medio de tablas o cuadros. Por lo general apelando a los conocimientos propios de la Estadística. 
insuficiencias significativas en la formación de los maestros: i) su insuficiente formación para trabajar en equipo, ii) su insuficiente formación para escribir sobre sus experiencias, iii) su insuficiente formación teórica en su campo de enseñanza específico, y iv) su insuficiente formación para reflexionar sobre su lenguaje y sobre su práctica. Como puede leerse, no hablo de deficiencias, un término peyorativo y pesimista, sino de insuficiencias de su proceso de formación, algo que todavía no se ha logrado, pero puede lograrse, a condición de generar sus condiciones de posibilidad. Dichas insuficiencias, por lo demás, no son exclusivas de sus procesos formativos sino, más bien, comunes a casi todos los procesos de formación profesional en nuestras instituciones universitarias.

Para suplir la insuficiencia para trabajar en equipo - ese gran ausente de los currículos que orientaron nuestros procesos de formación, personal y profesional - hemos diseñado un modo interactivo de co-operación, lingüísticamente mediado, ya sea por la palabra oral, o por el texto escrito. Para suplir la insuficiencia para escribir sus experiencias, hemos diseñado un ejercicio intensivo en prácticas escriturales sobre procesos pedagógicos. Para suplir la insuficiencia de su formación teórica,- hemos diseñado un ejercicio intensivo de prácticas lecturales, individualmente trabajadas, pero colectivamente comentadas. Y, finalmente, para suplir la insuficiencia en la formación para la reflexión, hemos diseñado un ejercicio intensivo de prácticas de auto-observación y heteroobservación, mediadas por el audiovideo.

Bajo la categoría prácticas lecturales englobamos los ejercicios de lectura de textos sugeridos por los investigadores para mejorar el nivel teórico de las maestras. Bajo la categoría prácticas escriturales englobamos tres pasos de la secuencia metodológica: el diseño de clase, la elaboración del "paper" y el informe de ciclo, destinados a mejorar las competencias y generar el hábito requeridos para la escritura. Bajo la categoría prácticas de observación englobamos la auto-observación y la hetero- observación de la clase, con la ayuda del audiovideo, destinadas a mejorar las competencias y crear el hábito requeridos para la reflexión (reflexividad). Bajo la categoría prácticas de interlocución englobaremos los talleres de reflexión sobre el diseño, sobre el "paper", y sobre la elaboración del informe de Ciclo, los cuales están destinados a fomentar la conversación entre pares, y a cambiar la actitud frente a la formulación y recepción de críticas. El papel del registro audiovisual, soporte tecnológico de las técnicas de observación e interlocución, estará entretejido con la descripción de sus prácticas correspondientes.

\section{La objetivación del lenguaje mediante la escritura}

Si entendemos el pensamiento como lenguaje interiorizado (Vigotsky) la escritura de las experiencias pedagógicas es una forma de objetivar el lenguaje interior del maestro, ese lenguaje que solo él conoce, cuando conversa consigo mismo, en y desde su subjetividad. De modo que la conversión de ese lenguaje interior en lenguaje social, mediante la oralidad o la escritura, es una forma de trasladarlo, del ámbito subjetivo y privado de las disquisiciones individuales, al ámbito objetivo y público de la discusión intersubjetiva entre pares ${ }^{9}$ (objetivación del lenguaje).

Esta objetivación puede interpretarse desde dos ángulos: como referente objetivo, ofrece un medio de contraste para que el maestro compare su lenguaje interior con su lenguaje exterior y, en consecuencia, proceda a los ajustes del caso. Como referente común ofrece un soporte objetivo para garantizar la unidad de tema en la discusión inter-subjetiva, o interlocución crítica. No se evalúa ni se juzga la persona del colega, sino el texto que él (o ella) ha producido. De modo que la

9. Cuando decimos "entre pares", nos referimos a una discusión que acontece entre profesionales de un mismo campo de acción y/o conocimiento, sobre los problemas específicos de ese campo. 
interlocución entre pares se presenta como una discusión mediada por textos. Una característica de la discusión estrictamente académica.

Ya lo dijimos, pero queremos insistir: no es posible objetivar el sujeto de la práctica, sin objetivar el lenguaje del sujeto. Esta es la razón por la cual el proyecto indujo a los maestros a hacer ejercicios intensivos en tres tipos de prácticas escriturales: i) el diseño de clase; el cual ocurre antes de la realización de la clase, como una forma de planeación que se adelanta a prever tanto el sentido como los procedimientos para realizarla, ii) la elaboración de los 'papers', la cual ocurre después de la clase, como una forma de reflexión sobre su práctica, con base en el registro audiovisual y iii) la producción cooperativa del informe de ciclo, la cual ocurre al terminar el ciclo para recoger la experiencia y las lecciones que deja. Los tres tipos de prácticas apuntan a perfeccionar las competencias escriturales de los maestros, dada la importancia del lenguaje escrito en el mundo académico y profesional. $Y$ todos ellas apuntan a sugerir la relación entre escritura de la experiencia y construcción del saber pedagógico.

\section{La práctica del diseño de clase}

Los investigadores recogen de Donald Schön (1992) la concepción de que la educación es un arte y el educador un artista. Puesto que toda la tradición de la formación para el arte le ha dado un lugar eminente al diseño de la obra, los investigadores sostienen que la cultura y la lógica del diseño deben formar parte de las competencias profesionales del maestro. Por esta razón el primero de todos los procedimientos, de la metodología en construcción, apunta a ejercitar al maestro en la práctica del diseño, solicitándole ejercicios de diseño de sus clases, por escrito, con el fin de someterlos a discusión en el taller de interlocución con sus pares. En este sentido, el ejercicio del diseño tiene una doble dimensión: como práctica escritural y como práctica de planificación.
Consideramos "el diseño de clase" como un momento constitutivo de la práctica pedagógica, y no simplemente como un ejercicio de calistenia previo, y facultativo, para entrar en el escenario de la clase. De modo que la práctica pedagógica no comienza cuando el profesor entra al aula de clase, sino mucho antes, cuando él se pregunta qué quiere hacer, para qué lo quiere hacer y cómo lo va a hacer ${ }^{10}$.

En su calidad de práctica escritural, el diseño tiende a modificar el hábito de llegar a la clase con un plan improvisado, "en la cabeza" del maestro. Elaborar un plan por escrito tiene muchas ventajas: la primera que el maestro se ve llevado a explorar el ámbito de las disciplinas que valoran la creatividad y la imaginación propias de la actividad de diseño, para salir de la rutina institucional en que se encuentra apresada su propia práctica pedagógica. La segunda que, al intentar visualizar la secuencia de sus procedi-mientos, por medio de la escritura, se hace mucho más evidente la necesidad de ordenar las actividades y someterlas a una cierta lógica, presentando objetivos, metodología, temáticas y actividades, organizados dentro de un marco temporal limitado. La tercera ventaja es que contribuye al desarrollo de las compe-tencias escriturales, requeridas para su ejercicio profesional, las cuales se hacen mucho más apremiantes en el caso de los maestros que enseñan lectura y escritura, algunos de los cuales tienen dificultades para presentarse como modelos en el arte de leer y escribir. Finalmente, el texto escrito que resulta de sus prácticas escriturales le sirve de registro para acumular su experiencia y de vehículo para compartir con sus colegas los discursos interiores y las preguntas que van surgiendo en el decurso de su práctica profesional.

\section{La práctica de la elaboración del 'Paper'}

Como práctica escritural, el propósito del 'paper' es consignar las vivencias que el maes-

10. Habría que agregar que tampoco termina cuando el profesor sale de la clase, porque entonces comienzan las preguntas por los aciertos o desaciertos en la puesta en escena. 
tro experimenta al observarse a sí mismo en el video, relacionadas con los aspectos que más atrajeron su atención, con los sentimientos y emociones que se suscitaron al verse a sí mismo o al ver a sus estudiantes, y con las lecciones que derivan de su auto-observación. La escritura de la experiencia facilita el tránsito de lo inconsciente a lo consciente y, por consiguiente, el tránsito de la experiencia al saber.

\section{La práctica de la construcción del informe de ciclo}

Como práctica escritural, el propósito del informe de ciclo es el de sistematizar y evaluar las actividades que se llevaron a cabo, pero especialmente recoger las lecciones que se van derivando de los procesos de retroalimentación y de las discusiones que se producen en los escenarios de interlocución. Como práctica cooperativa, el propósito es contribuir al aprendizaje del trabajo en equipo. Un aprendizaje que, desgraciadamente, no formó parte, de manera explícita, de los currículos con que nos formamos en el nivel básico y en el profesional.

\section{La objetivación de la práctica mediante el audiovideo}

Disciplinas como la medicina y la psiquiatría han inventado en el decurso de su historia la forma de objetivar su práctica, y han recogido dividendos significativos de esta inven-ción. La pedagogía, sin embargo, ha llegado un poco tarde a este proceso. Al no tener la oportunidad de observar su obra desde afuera, el maestro está privado de una herramienta y un procedimiento, poderosamente eficaces, para construir el conocimiento de su práctica.

Ante la imposibilidad de que el maestro se observe a sí mismo en el mismo momento en que realiza su clase, el desarrollo tecnológico nos ha ofrecido una herramienta y una oportunidad para subsanar este vacío: la videograbación, que es también audiograbación. Por su medio hemos logrado objetivar la obra del maestro, su actuación, su cuerpo, su gesticulación, su palabra, sus modos de interacción con los estudiantes, la disposición de sus escenarios, etc.

El(la) maestro(a) ha encontrado en este medio de registro una experiencia de reconocimiento de su propia existencia, en el escenario que le es propio. En el audio-video se ha visto como retratado, física y sicológicamente, y se ha puesto en condiciones de comparar la experiencia de verse en el espejo con la experiencia de verse en el video. Por su medio, finalmente, el maestro ha podido observar-se, o autoobservarse. Una modalidad de la observación en donde el maestro es, a la vez, el sujeto y el objeto de la observación. En cuanto sujeto que observa, está expresado en el prefijo “auto", y en cuanto objeto observado, está expresado en el pronombre reflexivo "se".

Hablo de una práctica de auto-observación y no de una práctica de introspección. El objeto de análisis de esta última práctica reposa en el interior del sujeto, y sólo él puede tener acceso a dicho objeto. En el caso de la auto-observación, el objeto de análisis ha sido puesto afuera del sujeto, mediante el registro audiovisual, para que el maestro lo pueda analizar en diferido, pero en circunstancias más favorables.

De modo que el audio-video, en cuanto objetivación de la práctica del sujeto, afuera del sujeto, se convierte: a) en un referente objetivo para que el maestro, como sujeto individual pueda mirarse a sí mismo, en un ambiente privado y tranquilo, y b) en un referente común para que otros sujetos (sus pares o los investigadores) puedan observar lo mismo. En el primer caso podemos decir que el maestro ejerce una práctica de auto-observación, y en el segundo caso podemos afirmar que sus pares y/o los investigadores ejercen una práctica de hetero-observación en un ambiente de inter-locución.

Como todos los registros, el audiovideo fija las acciones, los gestos y las palabras del maestro, y los libera de la posibilidad de desvanecerse en el tiempo y de desteñirse en la 
memoria de los sujetos. Si lo comparamos con el registro escrito, pasado ya por los tamices del sujeto que escribe, el registro audiovisual se revela como un texto más complejo, abierto a la posibilidad de lecturas múltiples.

Diferentes actores, desde diferentes puntos de vista, pueden: ver la película en cámara lenta, "retroceder la película" para detenerse en una escena que amerita más atención, repetirla cuantas veces sea necesario (replay) cambiar el centro de atención en cada oportunidad, fragmentar el texto en múltiples partes para detallar y hacer una lectura más fina de una escena particular, centrar su atención unas veces en el video y otras en el audio, etc.

Debido a la complejidad de lo que ocurre en el aula, de la cual forma parte el maestro, la experiencia de observación del video permite reconocer algunos aspectos relevantes que se pueden pasar por alto en el momento de la clase, pero que pueden ser recuperados a través del video. En este sentido, el video ofrece la ventaja de poner al maestro en unas nuevas condiciones para la observación porque no tiene que centrar su atención en el contenido de su clase, ni estar pendiente de la disciplina, ni del procedi-miento didáctico que quiere implementar, ni del plan B.

Resumiendo: el registro audiovisual, punto de soporte y de partida para el análisis y la interpretación posterior, fue la herramienta a la que apelamos para generar un proceso cualitativamente distinto a la introspección: la auto-observación. Nos facilitó la construcción de un camino metodológico para la observación del maestro en acción. Y cumplió una doble función: sacar la clase del aula, para llevarla, en primera instancia, a un ámbito de reflexión individual, en donde el maestro pueda verse a sí mismo desde afuera. $Y$, en segunda instancia, para llevarla a un ámbito de discusión pública, en donde sus colegas, junto al maestro, pueden observar su actuación y formularle las observaciones y sugerencias que consideran convenientes.

\section{La objetivación del cuerpo y las emociones correspondientes}

No es el propósito de este trabajo adentrarnos en las honduras de los procesos por medio de los cuales construimos imágenes de nosotros mismos, pero lo cierto es que estos constructos culturales están mediados por las imágenes de nuestros propios cuerpos; y que nuestra auto-estima está, en gran medida, determinada por las emociones que nos rebotan el espejo o los otros. No es de menor importancia, por consiguiente, que el registro audiovisual les ofrezca a las maestras una objetivación de sus cuerpos, y les suscite una serie de emociones.

Dejemos que sean ellas mismas quienes nos expresan sus sentimientos de complacencia o de asombro ante la experiencia de ver su propio cuerpo ${ }^{11}$.

"He tenido siempre el problema del tono de la voz que es un poco alto, en el video lo confirmo y he tratado de bajarle un poco, estoy segura que lo estoy manejando mejor, pero en la filmación vuelvo a elevarlo (no es excusa) tal vez me pongo nerviosa" (M3).

"la voz se me cambió, la figura en TV del cuerpo cambia” (M2).

"Ya no tengo 25" (M3).

"Es curioso verme y descubrir cómo soy, tanto física como psicológicamente... física [mente] porque no es la misma sensación verme en el video y verme en el espejo. Psicológicamente [porque] es muy intere-sante ver cómo se actúa ante una situación, cómo se enfrentan los retos y qué errores se cometen" (M4). "permite verme desde el punto de vista físico, reflexiono sobre mi quehacer pedagógico, mis mañas, como cortar la cinta [con la boca], o borrar el tablero [con las manos]" (M5).

11. Por convención nos referimos a las seis maestras que trabajaron con nosotros, como M1, M2, M3, M4, M5 y M6. Las citaciones están tomadas de las respuestas que ellas dieron al "Cuestionario de Aprendizajes" que se incluye, como anexo, en el Informe final de nuestro proyecto. 
La experiencia, sin embargo, no se agota en la complacencia de verse a sí mismas. Son múltiples las emociones que se les escapan, sin posibilidad de control: miedo, nervios, ansiedad, vergüenza, alegría, tristeza, sorpresa, etc. Es la primera vez que ven sus cuerpos "desde afuera".

"Al observar el video me sentí bastante bien en mi ser de educadora. Le agradecí a la vida y a Dios por permitirme ver una clase mía desde afuera, poder responderme preguntas que siempre tenía al terminar una clase en la cual yo como docente decía “salió bien'” (M1).

"Al mirar el video sentí nervios, ansiedad y pena, ya que no es muy usual verse desde ese punto, es decir desde lo externo, desde una perspectiva fuera de sí" (M4).

"Alegría ya que es la primera vez que me graban en 23 años de educación” (M2).

"Asombro porque es la primera vez que me veo en mi trabajo. Me veo seria, nerviosa $y$ preocupada. Ya no tengo 25" (M3).

“...fue bastante novedoso y una experiencia única el primer video, sobre todo después de tantos años de experiencia docente. El poder regresar la película, ver detalles, observarse uno mismo, analizar el comporta-miento de los estudiantes hace que uno reflexione el "por qué un niño o niña es asi”" (M5).

Al principio predominaron las emociones de signo negativo, pero con el tiempo se fueron disolviendo. Las maestras comenzaron a reconocer que los videos no eran un instrumento con intenciones de evaluación, control o vigilancia, sino un medio para que ellas pudieran observarse, reconocerse y autoevaluarse, ejerciendo la especificidad de su oficio, y su modo de relación con los estudiantes.

\section{La objetivación de los niños los vuelve más visibles}

No estamos hablando de tratar a los niños como objetos. No, queremos decir que la objetivación que el registro audiovisual hace de los niños, los vuelve más visibles. Paradójicamente la mayor parte de los niños están invisibilizados durante la clase. El(la) maestro(a) tiene su atención concentrada en el discurso que está haciendo, en lo que está escribiendo en el tablero, en el acetato que va a mostrar o está mostrando, etc. En fin, hay muchos aspectos que escapan a su observación durante la clase, que el video los recoge para que él pueda volver sobre ellos.

Obviamente, para que los niños se hagan visibles y pasen al primer plano, el maestro debe centrar su atención sobre ellos, y dejar de mirarse a sí mismo. Entonces aparece lo que estaba ocurriendo en el aula, pero que el maestro no advirtió. Otras facetas del aula se revelan. La imagen que el maestro tiene de algunos de sus estudiantes puede comenzar a removerse. El video le ofrece observar actuaciones de los estudiantes que no pudo advertir en el desarrollo de su clase, le permite verlos de otra manera, como en cámara lenta, y cuantas veces lo quiera. En este sentido, le ofrece un referente distinto para reconstruir la imagen que tiene de ellos, con el consiguiente riesgo de que la transformación de la imagen pueda llevarlo a modificar su modo de relación con ellos.

"La capacidad de entender la importancia de [...] ver a los niños en diferentes circunstancias, ya que no tenemos la posibilidad de verlos o visualizarlos a todos" (M2).

“... fue bastante novedoso [...] poder regresar la película, ver detalles, [...] analizar el comportamiento de los estudiantes hace que uno reflexione el "por qué un niño o niña es asi” (M5).

"El observar el video me ha servido par mejorar o corregir algunos aspectos, como [...] tener cuidado en el manejo de la participación de los niños” (M3).

"Veo cómo algunos niños son muy pasivos, poco participativos y buscan la forma de depender de los compañeros" (M3).

"El video es una herramienta útil ya que se 
pueden descubrir muchísimas facetas que, a simple vista, no se pueden observar; cada vez que se mira se van a encontrar más potencialidades o errores, que van a ayudar a fortalecerlas o a superarlos” (M4).

\section{Las prácticas lecturales}

Con el fin de potenciar el nivel teórico de las maestras, pusimos a su disposición dos lecturas fundamentales: la primera contenía la descripción de una experiencia-tipo de investigación-acción pedagógica ${ }^{12}$ y la segunda un texto relacionado con la enseñanza de la lectura y la escritura (Jurado, 1999). La primera trataba de dar a conocer los fundamentos teóricos de la IAPE y, sobre todo, el ciclo procedimental diseñado por los investigadores en el proyecto anterior, con el fin de ofrecer un panorama introductorio a la experiencia que iniciábamos. La segunda apuntaba a sugerirles a las maestras la necesidad de fundamentar su práctica de enseñanza de la lectura y la escritura en los recientes desarrollos de disciplinas como la lingüística, la sicolingüística, la sociolingüística y la didáctica de la lengua.

Sugerimos una metodología de lectura y reservamos un tiempo para verificar su comprensión. Los resultados nos pusieron ante la evidencia de dos obstáculos que estarian interfiriendo a todo lo largo del proceso: las estrecheces de tiempo en que se mueven las maestras, y las limitaciones que revelan sus procesos formativos para comprender a cabalidad el lenguaje especializado de esos textos. No obstante estas dificultades, las maestras recogieron algunas ideas claves para el cuestionamiento de sus prácticas. Un ejemplo:

"De las ideas que aparecen en las lecturas, me he cuestionado un poco sobre la forma como he estado exigiendo la corrección de ortografía, la letra, pues me estoy dando cuenta de que esto no es lo más importante, debo respetar lo que el niño o niña escribe; sus ideas y las "ganas" de querer hacer la cosas, son más valiosas que las arandelas; claro que no debo descuidar esto, pero sí darle menos importancia, ya que es por eso, y lo digo con conocimiento de causa, que es traumático que siempre le vean lo negativo, que lo pongan a corregir y no le den la libertad de expresar lo que quiere y lo que siente” (M3).

Y, en general, percibieron la relación de las lecturas con la didáctica de la escritura en puntos importantes como la prioridad del proceso de aprendizaje sobre los resultados, la necesidad de respetar los ritmos propios de los niños, así como sus diferencias y contextos.

"Una muy buena idea es la forma como se debe dejar al niño-niña, que se inicie en la escritura a partir de sus "garabatos"; y en la lectura a partir de leer sus dibujos o señales o signos que son importantes para él" (M3). "a los niños no se les debe generalizar y, por lo tanto, se debe respetar su evolución en el aprendizaje de la lectura y la escritura" (M3). "lo más importante en el aprendizaje no es el resultado, sino el proceso que tiene cada niño para obtener las metas propuestas" (M4).

"Como docente debo tener en cuenta las necesidades de cada niño y reconocer que cada uno es diferente; $y$ sus experiencias $y$ contextos son únicos" (M4).

"Me llama la atención lo que se dice de los libros, que no se debe manejar uno solo $y$ que la función no es pasar el libro al cuaderno" (M3).

"somos muy dados a hablar mucho y escribir росо” (M3).

"La escritura y la lectura tienen un proceso, el cual se construye teniendo en cuenta las fortalezas y debilidades de cada niño" (M5).

"La parte oral, escrita, gráfica, mímica juega un papel muy importante en la significación” (M5).

12. Nos referimos al texto sobre el Proyecto Aluna, ya mencionado anteriormente. 


\section{Las prácticas de interlocución crítica entre pares}

Dijimos, al comienzo, que el papel de la interlocución crítica es el de fomentar la conversación entre pares, y cambiar su actitud frente a la formulación y recepción de críticas. Este propósito se revela de suma importancia en un medio, como el nuestro, no educado para el debate, en el que oscilamos entre el "comité de aplausos" y la obstrucción indiscriminada a las propuestas del otro, por razones personales. $\mathrm{Y}$, con mayor razón, cuando las críticas están atoradas en las gargantas y se silencian, por inseguridad o por temor, o por el escepticismo aprendido, después de tantas experiencias en las que no ha servido para nada el haberse expresado.

En este sentido, el taller de interlocución crítica ha creado un ambiente favorable para que las maestras se decidan a hacer críticas y a recibir críticas. Con respecto a la formulación de críticas, el asunto se veía tenso, las maestras estaban un poco temerosas, con el tiempo fueron ganando más confianza para hacerlo. Con respecto a la recepción de críticas pasó algo parecido. Poco a poco comenzaron a entender que el saber de las otras podía ayudarlas a crecer como profesionales, y que su apertura a la crítica era una oportunidad de aprendizaje. Entendieron también que su nivel de recepción de las críticas estaba relacionado con la capacidad de escuchar.

"He logrado aprender que cada persona o ser humano necesita del otro para mejorar, ya que cada uno tiene [...] una serie de conocimientos que aportan a los demás” (M4).

"Por otra parte, es importante el estar abiertos para la crítica ya que es esencial para corregir los errores que se cometen y fortalecer las potencialidades" (M4).

"Saber que debo corregir algunas cosas, que lo que opinan mis colegas debe ser para crecimiento de mí misma como docente" (M5).

"Descubro que mis colegas me pueden dar luces de acuerdo a su propia experiencia" (M5).
"Ser más segura con lo que hago, en cada una de mis clases, y así mismo corregirme $o$ que me corrijan" (M6).

Llama poderosamente la atención que una maestra reconoce, como un gran logro, haber superado "un poco el temor de participar con mis opiniones”, y atribuye el origen de ese temor al estilo pedagógico de la época en que se formó. La tildaban de "bruta" cuando no acertaba.

“Otro logro es poder dejar un poco el temor de participar con mis opiniones, aunque en algunos momentos veo que son un poco pobres, tal vez debido a la forma como aprendí, o me tildaban de bruta cuando no acertaba" (M3).

En general se percibe un cambio de actitud en las maestras: se las ve más desinhibidas para compartir sus opiniones, para reconocer sus errores y para recibir las críticas.

"Ha servido para una retroalimentación del quehacer cotidiano de cada maestro y así ayudar al proceso de aprendizaje de nosotras como maestras" (M2).

"El no cohibirse ni reservar ningún comentario, sentimiento o emoción al hablar sobre nuestro quehacer docente" (M4).

"El aceptar errores y críticas para mejorar" (M4).

\section{Las maestras comparan y concluyen}

¿Cómo evaluaron las maestras su participación en la experimentación de esta modalidad de la 1APE? Las respuestas son más que abundantes. Entre todas ellas, sobresale una que es preciso compartir, porque implica una comparación de los métodos de capacitación tradicional con el método de investigación-acción pedagógica que nosotros pusimos a prueba en el Colegio Fundación Santa María. En su respuesta, la maestra califica a los primeros de "recetas" que, unas veces sirven y otras no, y aduce dos razones 
para sustentar su afirmación: primera, que el recurso humano que asiste a estos eventos de capacitación es muy heterogéneo; y segunda, que el mismo método no puede funcionar de la misma manera para todos.

Con estas premisas, concluye que es más productiva, y a la larga más eficiente, la investigación de la práctica pedagógica que la capacitación, porque en el método de investigación-acción "se socializan las experiencias" y se aprende de la experiencia de los otros. Si se explicita aún más lo que dice esta maestra, es claro que ella invalida la pretensión de capacitar a los maestros por medio de dispositivos metodológicos homogeneizantes y, en cambio, valora positivamente el papel que puede desempeñar la socialización de experiencias en el perfeccionamiento profesional.

“...los métodos que se dan en las capacitaciones, de alguna manera, son como recetas, unas veces sirven, otras no, puesto que el material humano es heterogéneo y para todos no funciona el mismo método; por eso los proyectos de investigación son más productivos porque se socializan las experiencias y esto enriquece nuestro quehacer" (M3).

También me parece importante recoger la contraposición que hace una de las maestras entre "clase magistral" e "investigación entre todos”, porque está implicando una comparación entre la práctica pedagógica individual a la cual estaba habituada, antes de participar en este experimento, y la práctica pedagógica cooperativa que tuvo la oportunidad de conocer y experimentar, dentro del marco de nuestro proyecto. En su respuesta es claro que ella privilegia esta última modalidad de la práctica, como un cambio significativo en el modo de trabajar y de construir conocimiento:

"el tiempo ha cambiado mucho y hay que ser parte de ese cambio, ya que no hay clases magistrales, se construye el conoci-miento y la investigación entre todos" (M5).
"Somos agentes de cambio y no todo está terminado, aunque llevemos muchos años de experiencia, yo no lo se todo" (M5).

\section{La especificidad del modelo}

Al llegar a este punto es prácticamente inevitable preguntarme por la especificidad de lo que hemos hecho. El primer rasgo, que aparece como distintivo, es el carácter co-operativo de esta modalidad de la IAPE. A diferencia de otras modalidades en las que se ha puesto a trabajar a una pluralidad de maestros en forma paralela, cada uno por su lado, con un objeto de estudio diferente, para presentar cada uno su propio caso de investigación, en nuestro proyecto se logró integrar un verdadero equipo de maestras, que actuaban sinergizadas alrededor de un único objeto de estudio, transversal al currículo: la enseñanza de la lectura y la escritura.

Las prácticas pedagógicas de las maestras ocurrieron, cada una de ellas, en sus respectivas aulas de clase, con sus particularidades didácticas, pero el proyecto de investigación era el mismo, el objeto de estudio era el mismo, la metodología de trabajo colectivo era la misma, las orientaciones teóricas que se impartieron eran las mismas para todas. El escenario de interlocución entre pares fue siempre el mismo y, más allá de la pluralidad de los actos, cuidadosamente distribuídos en el tiempo (un año y medio), la unidad de la obra sobresale lo suficiente para hacerse notar.

Un proyecto común sinergiza, con-voca las voces plurales de los(las) maestros(as) para que se hagan oír, suscita la conversación entre ellos(as), despliega una cultura de la coordinación. La conversación va tejiendo el equipo y el camino, y va transformando el lenguaje y la práctica. En el escenario del proyecto, como en todos los escenarios, se traman las conversaciones alrededor del objeto, el camino y los horizontes. Las conversaciones suscitan compromisos (léase: co-promesas), es decir: promesas que nos hacemos mutuamente para avanzar en el camino, responsabilidades que 
nos distribuimos para repartir la carga, tareas que tienen sentido para la construcción de una obra común, cooperativa, interactiva. Se teje la pluralidad y se disuelve la dispersión.

La modalidad de la IAPE que hemos puesto a prueba se revela como un dispositivo complejo, creador de condiciones y de ambientes para cultivar la argumentación y la interlocución crítica entre pares, mejorar las competencias lecturales y escriturales, escudriñar y reorientar las prácticas, racionalizar la acción y afianzar el hábito de la reflexión. Favorece el aprendizaje del trabajo en equipo, sin olvidar la necesaria distribución de responsabilidades personales e intransferibles. $Y$ pone a disposición de los maestros un escenario original y un ambiente único para la auto-observación, con la ayuda del registro audio-visual, referente objetivo para la discusión.

La capacidad de esta herramienta para objetivar al sujeto de la práctica pedagógica, en un ámbito de interlocución crítica y responsabilidad compartida, crea las condiciones para que la subjetividad individual de los maestros se sienta incluída en una subjetividad colectiva que es, finalmente, la responsable de la construcción de sentido. Al pasar de una práctica pedagógica individual a una práctica pedagógica institucional, y de un estilo individual de reflexión a un estilo colectivo de reflexión sobre la práctica, la determinación del sentido pasa a ser una responsabilidad del colectivo. Es decir: un asunto de interés público.

\section{¿Aplicación o re-invención?}

El texto que escribo, para poner en circulación la memoria de este experimento con una modalidad de la IAPE que, a falta de un mejor término, denomino un "artefacto cultural”, se me antoja semejante a la escritura de una partitura. Todas las claves para acceder al paisaje teórico y procedimental están indicadas. Es susceptible de variaciones y adaptaciones movidas por la imaginación, pero no es posible copiarla ni aplicarla de una manera mecánica. No está diseñada para producir los mismos re- sultados, a pesar de los contextos sino, al contrario, para que sus resultados estén en sintonía con el contexto. Como todas las partituras, necesita la mediación de un intérprete cualificado para poder ser re-inventada, re-creada y reposicionada en el escenario.

Este artefacto cultural, como cualquier otra metodología, tiene de más y tiene de menos. No está por encima del bien y del mal, ni está exento de riesgos. No es que sea fácil echarlo a andar, pero es bien difícil mantenerlo en funcionamiento durante un período de tiempo prolongado. Entre los riesgos que vienen a la mente, pueden señalarse: el riesgo de convertirlo en una secuencia mecánica de "pasos", sin comprender su lógica interna, el de centrar demasiado a los maestros sobre su práctica de aula, descuidando los modos de articulación de la institución escolar con sus contextos socioculturales. Y, finalmente, el más preocupante: su disposición para ser utilizado por tirios y troyanos, al servicio de cualquier "arbitrario cultural"13.

Hay argumentos suficientes para pensar que estamos ante una auténtica innovación pedagógica, de insospechables consecuencias para el futuro de la institución escolar: el poder de este artefacto para cuestionar y desmontar los presupuestos constitutivos de la estructura interna de la práctica pedagógica (capacidad heurística), el poder para sinergizar inteligencias, voluntades y emociones en torno a la construcción de sentido para sus prácticas colectivas (capacidad organizacional) y, finalmente, el poder para diseñar y hacer viables alternativas de articulación entre la escuela y su contexto (capacidad prospectiva), hacen de este artefacto un poderoso dispositivo de constitución de una subjetividad colectiva.

Pero lo más importante de este balance, lo que definitivamente hace de esta propuesta metodológica una experiencia significativa, es que con este "artefacto cultural" el maestro sale de su

13. Remito a y recomiendo las sabias reflexiones del Profesor José Carlos Libâneo (2002). 
aislamiento en el aula para integrarse al colectivo, y la práctica pedagógica sale de su ocultamiento en un ámbito privado para trasladarse a un ámbito de discusión e intervención públicas. El sentido de la práctica pedagógica y el modo de articulación de la escuela con su contexto, son un asunto de interés público. La responsabilidad compartida, en consecuencia, ha de considerarse como el primer principio regulador del ejercicio profesional del colectivo pedagógico, de cara a una sociedad que exige transparencia y rendición de cuentas (accountability), pero también, y sobretodo, nuevos horizontes y nuevos rumbos para la (re)construcción del tejido social.

\section{Referências Bibliográficas}

AGUDELO, R.; BALLESTEROS, B. Comparación de dos métodos de enseñanza de lectura y escritura. Bogotá: Centro de Investigaciones de la Universidad Pedagógica Nacional - CISP, 1983.

AGUDO, S. et al. Interacción y competencia comunicativa: experiencias sobre lectura y escritura en la escuela. Bogotá: Universidad Nacional de Colombia - Proyecto RED, 2000.

ALVARADO, L. E. (Org.). Formación de profesores en América Latina: diversos contextos socio-políticos. Bogotá: Ediciones Antropos, 2003.

ÁVILA PENAGOS, R. (Org.). La investigación acción pedagógica: experiencias y lecciones. Bogotá: Antropos, 2003.

(Org.). El sujeto, la cultura y la dinámica social. Bogotá: Ediciones Antropos, 2005.

BRUNER, J. La importancia de la educación. Barcelona: Paidós, 1987.

CALVO, G. et al. El aula reformada: un análisis de las prácticas pedagógicas en lectura y escritura a la luz de la reforma educativa. Bogotá: Universidad Pedagógica Nacional, 2001.

FERREIRO, E.; GÓMEZ, P. (Orgs.). Nuevas perspectivas sobre los procesos de lectura y escritura. México: Siglo XXI, 2000.

JURADO F. Alfabetización. Teoría y Práctica. México: Siglo XXI, 2001.

Investigación, escritura y educación: el lenguaje y la literatura en la transformación de la escuela. Bogotá: Universidad Nacional de Colombia, 1999.

LERNER, D. Leer y escribir en la escuela: lo real, lo posible y lo necesario. México: Fondo de Cultura Económica, 2001.

LIBÂNEO, J. C. Reflexividade e formação de professores: outra oscilação do pensamento pedagógico brasileiro? In: PIMENTA, S. G.; GHEDIN, E. (Orgs.). Professor reflexivo no Brasil: gênese e crítica de um conceito. São Paulo: Cortez, 2002.

As políticas de formação de professores no contexto da reforma universitária: das políticas educativas para as políticas da educação. In: VII ENCONTRO DE PESQUISA EM EDUCAÇÃO DO CENTRO-OESTE (EPECO), 2004, Goiânia. Anais. Goiania: UFG, 2004. CD-ROM.

MELICH, J. Del extraño al cómplice. Barcelona: Antropos, 1997.

MERCER, N. La construcción guiada del conocimiento. Barcelona: Paidós, 1997.

PÉREZ ABRIL, M. La investigación sobre la propia práctica como escenario de cambio escolar. Pedagogía y Saberes, Bogotá, n. 18, 2003. 
ZAMOSC, L. Campesinos y sociólogos. Cuadernos de Agroindustria, Bogotá, n. 14 y 15, 1985.

ZEA, L. F. La organización como tejido conversacional. Medellín: Fondo editorial de EAFIT, 2004.

Recebido em 06.06.05

Aprovado em 19.10.05

Rafael Avila Penagos es Doctor en Sociología, Universidad católica de Lovaina, Bélgica. Magister en Dirección Universitaria, Universidad de los Andes, Bogotá, Colombia. Profesor del Universidad Pedagógica Nacional, Bogotá, Colombia: Doctorado interinstitucional en Educación; Maestría en Educación; Especialización en investigación social. Investigador en ciencias sociales. Y autor de libros en educación y pedagogía. 